\title{
Pb-Free Solder Joint Thermo-Mechanical Modeling: State of the Art and Challenges
}

\author{
JEAN-PAUL M. CLECH, ${ }^{1,5}$ RICHARD J. COYLE, ${ }^{2}$ and BABAK ARFAEI ${ }^{3,4}$ \\ 1.-EPSI Inc., P. O. Box 1522, Montclair, NJ 07042, USA. 2.-Nokia Bell Laboratories, Murray \\ Hill, NJ, USA. 3.-Ford Motor Company, Dearborn, MI 48124, USA. 4.-Binghamton University, \\ Binghamton, NY 13902, USA. 5.—e-mail: jpclech@aol.com
}

\begin{abstract}
Acceleration factors and predictive life models are of use to build-in board assembly reliability and estimate solder joint life at the design stage. They allow designers to answer management and end-users' reliability questions. This paper reviews the grand families of solder joint reliability models that can help answer these types of questions. Different categories of models were reviewed, examples were provided and model limitations were discussed. Emphasis is on engineering models for $\mathrm{Sn}-\mathrm{Pb}$ and $\mathrm{Pb}$-free assemblies. Differences in the microstructure and failure mechanisms of near-eutectic Sn-Ag$\mathrm{Cu}$ solders versus $\mathrm{Sn}-\mathrm{Pb}$ are also reviewed, as they present new challenges to the development of thermo-mechanical models for surface mount assembly reliability assurance.
\end{abstract}

\section{INTRODUCTION}

Solder joints provide mechanical and electrical connections between electronic components and the substrates to which they are attached. Whether Pb-based or Pb-free, mainly $\mathrm{Sn}-\mathrm{xAg}-\mathrm{yCu}$ (SAC) alloys, with $\mathrm{x}$ and $\mathrm{y}$ being the percent weights of $\mathrm{Ag}$ and $\mathrm{Cu}$, solder joints are at risk of failing in a wear-out mode with creep-fatigue damage accumulating over time, due to thermomechanical stresses and strains imparted by the environment, power on and off cycles, and differences in the thermal expansion of interconnected parts. These conditions eventually lead to cracked, electrically open solder joints. Reliability is defined in industry standards as "the ability of a product to function under given conditions and for a specified period without exceeding acceptable failure levels". ${ }^{1,2}$ The goal of solder joint reliability assurance programs is to ensure that failure rates remain below an acceptable level by the end of the design life. In critical applications such as flight or space avionics or medical products, the goal is for solder joints to remain failurefree throughout the design life. To achieve these goals, it is essential to understand and quantify the loads, deformations and failure mechanisms experienced by solder interconnects in the field. Accelerated test results can then be extrapolated to field conditions by means of acceleration factors (AFs) using an appropriate model to bridge the gap between test and use conditions.

The development of AFs and predictive life models is a complex task, attempting to capture the physics of solder joint deformations, the main effects of board/component/assembly geometry and material properties and their interactions, as well as the impact of process parameters on solder joint life. A multitude of life prediction models have been developed for near-eutectic $\mathrm{SnPb}$ assemblies over the years. All $\mathrm{SnPb}$ models come with their own error margins and limitations. The latter are not always stated clearly, leading to abusive use of the models beyond their realm of applicability. Once a model has been validated against test data, simulations can be run to answer questions that are of interest to physical designers and management alike.

$\mathrm{Pb}$-free legislation and the proliferation of $\mathrm{Pb}$-free alloys have made the job of physical designers more difficult than during the $\mathrm{SnPb}$ era. Short design cycles, compounded by an ever-growing choice of $\mathrm{Pb}$ free alloys, do not allow for an accumulation of empirical data as occurred over 50 years of $\mathrm{SnPb}$ use in electronic assemblies. This has led to an increased interest in the use of predictive life models. Within that context, this article discusses the requirements, challenges and ingredients of solder joint life models, as applied to $\mathrm{Pb}$-free solders. 
The discussion focuses on engineering models that are of practical use to designers. Advanced modeling techniques that attempt to capture finer details of damage mechanisms, crack initiation and crack propagation, with the need for special constitutive models and higher computational resources, ${ }^{3,4}$ are referred to briefly but their intricacies are beyond the scope of this paper.

\section{PARAMETERS THAT AFFECT SOLDER JOINT RELIABILITY}

When devices are powered on or off or when the ambient temperature changes, the difference in inplane thermal expansion between board and component leads to cyclic shear strains in solder joints of surface-mount assemblies. Figure 1 is a schematic of half-an-assembly of a surface mount package soldered onto a circuit board. Solder joints, shown in their initial vertical position, are deformed in shear. The shear angle due to the difference in thermal expansions of the board and component is the shear strain, with a maximum value $\Delta \gamma_{\max }$ that is attained when stresses in the solder joints have completely relaxed:

$$
\Delta \gamma_{\max }=\frac{L \cdot\left|\alpha_{\mathrm{B}}-\alpha_{\mathrm{C}}\right| \cdot \Delta T}{h_{\mathrm{S}}}
$$

$L$ is the maximum distance to neutral point $\left(\mathrm{DNP}_{\max }\right)$ from the neutral axis of the assembly to the outermost solder joints, $\alpha_{\mathrm{B}}$ and $\alpha_{\mathrm{C}}$ are the board and component in-plane coefficients of thermal expansion (CTEs), $\mathrm{h}_{\mathrm{S}}$ is the solder joint height or component stand-off, and $\Delta T$ is the temperature change between the cold and hot sides of the temperature cycle. The maximum shear strain $\Delta \gamma_{\text {MAX }}$ is typically less than one angular degree $\left(1^{\circ}\right)$, even under harsh conditions, but this amount of shear is large enough to induce solder joint cracking and eventually open joints under low-cycle fatigue conditions. That is, electrical failures occur in a few hundred to a few thousand cycles. The concern with board-to-component in-plane CTE mismatch is referred to as the global CTE mismatch problem, as opposed to the local CTE mismatch problem, ${ }^{5}$ which refers to solder joint damage due to CTE mismatches across solder joint interfaces between solder and board pads, or between solder and component pads or leads. Local CTE mismatches are mostly of concern in the case of peripheral leaded packages with a leadframe material having a low CTE, e.g., Alloy $42(58 \% \mathrm{Fe}-42 \% \mathrm{Ni})$ leads having a CTE of about $5 \mathrm{ppm} /{ }^{\circ} \mathrm{C}(1 \mathrm{ppm}=1$ part per million) which is small compared to a CTE of about $24 \mathrm{ppm} /{ }^{\circ} \mathrm{C}$ for Sn-based solders. ${ }^{5}$

Figure 1 shows over a dozen parameters that are entered in compact or finite element analysis (FEA) models, including geometric, board and component properties (CTEs, Young's moduli and Poisson's ratios). These parameters have been identified as having a significant impact on solder joint life under thermal cycling conditions. The availability of design parameters and material properties is critical to the development of predictive solder joint life models. This has long been the Achilles' heel of the model development process, as few experiments are documented with accurate values of design parameters and material properties.

In the case of plastic area-array packages such as the ball grid array (BGA) or chip-scale packages (CSPs), the package contents have a significant effect on solder joint life. It is thus critical to account for each material layer, its thickness and its material properties. This leads to another set of input parameters that are crucial to the development of predictive life correlations. Figure 2a illustrates the basic package multi-layer model that is used to derive the effective package CTE on the solder side of the package and the assembly stiffness that is used in

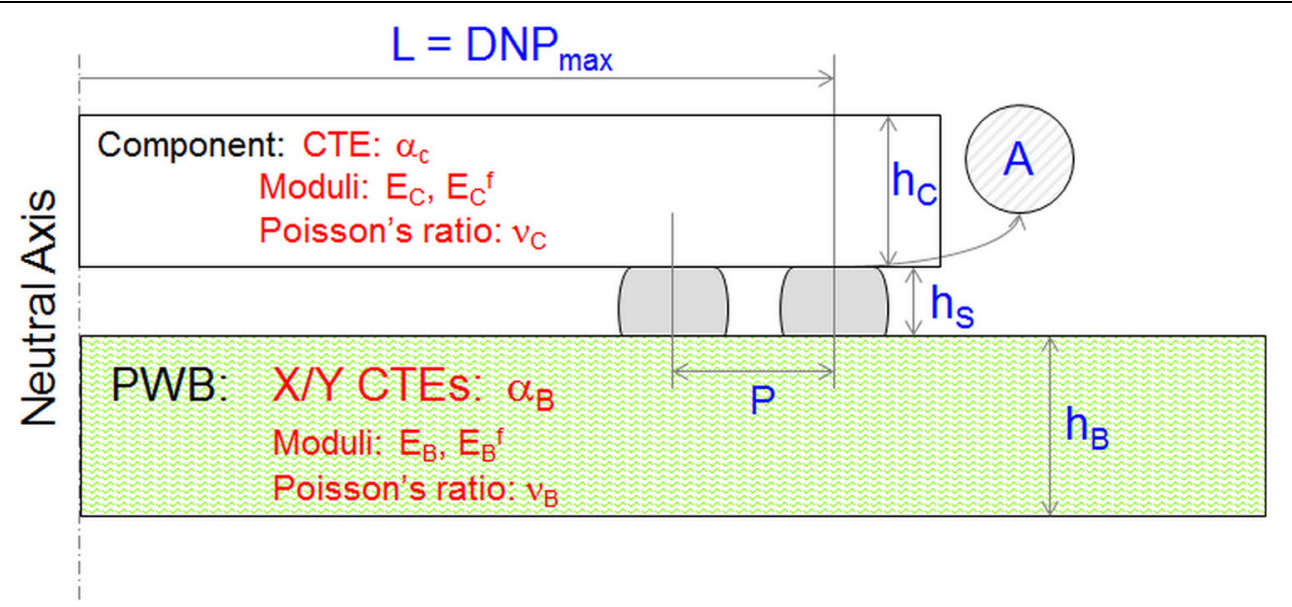

Fig. 1. Schematic of half-an-assembly showing 14 parameters that affect solder joint reliability: 6 geometric parameters (blue) and 8 material properties (red). $h_{B}$ thickness of board, $h_{c}$ component, $h_{s}$ solder joints; $A$ solder joint crack or load bearing area; $\alpha$ 's coefficients of thermal expansion, in $X / Y$ directions of circuit boards; $E$ Young's modulus, $E^{f}$ the flexural modulus; $v$ 's Poisson's ratios. Reprinted with permission from Ref. 7 (Color figure online). 


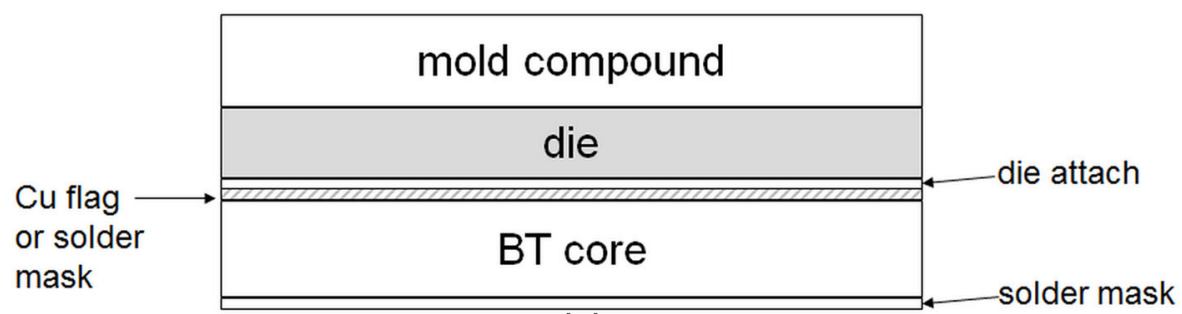

(a)

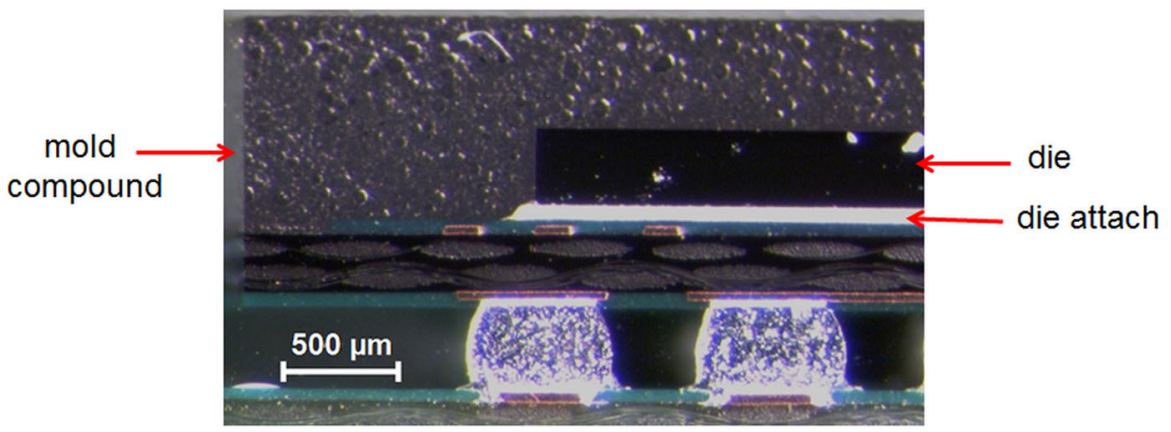

(b)

Fig. 2. (a) Schematic of multilayer construction in die area of area array packages such as BGAs or CSPs. Each layer, its thickness and material properties determine the effective CTE of the package on the solder ball side. Reprinted with permission from Ref. 8. (b) Cross-section of $192 \mathrm{I} / \mathrm{O}$ CABGA assembly highlighting package contents. The silicon die is attached to the substrate by means of a die attach material (thin white layer below the die).

compact strain energy models..$^{6-8}$ Figure $2 \mathrm{~b}$ shows an example of a BGA assembly cross-section. Material layers expand or contract and can stretch and bend as per Hall's thermo-mechanical model of multilayered structures, ${ }^{9}$ which provides for good estimates of the package's effective CTE. Relevant input parameters are layer thickness, CTEs, Young's moduli and Poisson's ratio for each layer of a plastic package (Fig. 2a). In some instances, it is necessary to account for temperature-dependent material properties. If package material properties are not available, accelerated test data cannot be used in the development of predictive life correlations. In other words, accelerated test results are not fully exploited and valuable information is forfeited that could have been fed into life data correlations. Package material characterization is crucial to solder alloy comparisons ( $\mathrm{Pb}$-free versus $\mathrm{SnPb}$ ). Everything else being equal, including die size and package geometry, $\mathrm{Pb}$ free packages may use different die attach, solder mask or molding compounds to accommodate higher reflow temperatures. Differences in these plastic- or epoxy-based materials lead to differences in package CTEs that need to be accounted for when comparing thermal cycling results for $\mathrm{Pb}$-free and $\mathrm{Sn}-\mathrm{Pb}$ assemblies.

\section{MODEL CHARACTERISTICS, COSTS AND BENEFITS}

An engineering model is a mathematical idealization of a real-world situation. For example, a structural analysis model using classical mechanics or FEA aids in the analysis of solder joint stress/ strain histories as well as board and component deformations. Models are also of use to determine $\mathrm{AFs}$ and extrapolate failure cycles from accelerated thermal cycling (ATC) to field conditions.

Life prediction models that are discussed in this paper are deterministic, probabilistic and empirical all at once. The "deterministic" aspect refers to the structural analysis features of the models. The "probabilistic" factor refers to models including a failure time distribution so that solder joint life can be predicted at a specified failure level (e.g., cycles to $0.01 \%$ failures). The "empirical" qualifier refers to the fact that predictive models include material constants, e.g., solder fatigue constants, and need to be calibrated against test data.

Modeling is a cost-effective way to estimate solder joint reliability, although the costs and the resources that are needed to run various models vary by orders of magnitude. Engineering models using a finite element code with creep capabilities require workstation computing power, a skilled finite element analyst and hours of computational time for each model run. Compact solder joint reliability models take advantage of classical mechanics to capture the response of boards and components. These compact models run in a couple of seconds on personal computers (PCs). Solder joint reliability modeling is also one to several orders of magnitude less costly than accelerated testing. Modeling offers significant time savings since a model of a soldered assembly can be built and run in a short amount of time, from a few hours to a couple 
Table I. Grand families of solder joint life prediction models, tabulated as per needed computational resources

\begin{tabular}{|c|c|c|c|c|}
\hline $\begin{array}{l}\text { Computational } \\
\text { resources }\end{array}$ & Model type, damage criterion & $\begin{array}{c}\text { Organization, model name } \\
\text { and/or author(s) }\end{array}$ & Solder alloys & Refs. \\
\hline \multirow[t]{4}{*}{$\begin{array}{l}\text { Calculator/spread- } \\
\text { sheet }\end{array}$} & \multirow[t]{4}{*}{$\begin{array}{l}\text { Modified Coffin-Manson, plastic } \\
\text { strain range }\end{array}$} & IBM, Norris-Landzberg & $\begin{array}{c}\text { High Pb } \\
\text { (95Pb5Sn, } \\
\text { 97Pb3Sn) }\end{array}$ & 10,11 \\
\hline & & HP, Miremadi et al. & SAC305 & 13 \\
\hline & & IPC/Engelmaier & Eutectic $\mathrm{SnPb}$ & $\begin{array}{c}1, \\
2,12\end{array}$ \\
\hline & & Engelmaier & SAC305/405 & 14 \\
\hline \multirow[t]{4}{*}{ Personal computer } & \multirow{4}{*}{$\begin{array}{l}\text { Classical mechanics/compact } \\
\text { models, strain energy density }\end{array}$} & AT\&T, CSMR model & Eutectic $\mathrm{SnPb}$ & 15 \\
\hline & & HP, FAIR model & Eutectic $\mathrm{SnPb}$ & 16 \\
\hline & & EPSI Inc., SRS model, Clech & Eutectic $\mathrm{SnPb}$ & 7 \\
\hline & & $\begin{array}{l}\text { EPSI Inc., Compact Strain En- } \\
\text { ergy model, Clech }\end{array}$ & SAC387/405 & 8 \\
\hline \multirow[t]{4}{*}{ Workstation } & \multirow[t]{2}{*}{ FEA, strain energy density } & Motorola/Amkor, Darveaux & Eutectic $\mathrm{SnPb}$ & $17-21$ \\
\hline & & Amkor, Darveaux & $\begin{array}{c}\text { SAC105, 205, 305, } \\
405\end{array}$ & 22 \\
\hline & $\begin{array}{l}\text { FEA, strain energy density, } \\
\text { inelastic strain range }\end{array}$ & Amkor, Syed & $\begin{array}{l}\text { Eutectic SnPb, } \\
\text { SAC305/405 }\end{array}$ & 23,24 \\
\hline & $\begin{array}{l}\text { FEA, strain range partitioning, } \\
\text { strain energy density }\end{array}$ & CALCE/U. Maryland, & $\begin{array}{l}\text { Eutectic } \mathrm{SnPb} \\
\text { SAC305/405 }\end{array}$ & 25,26 \\
\hline Supercomputer & $\begin{array}{l}\text { Advanced FEA, microstructural } \\
\text { evolution, crack initiation }\end{array}$ & $\begin{array}{c}\text { SANDIA National Lab., Frear } \\
\text { et al. }\end{array}$ & Eutectic $\mathrm{SnPb}$ & 3 \\
\hline
\end{tabular}

Illustrative examples of life prediction models as per solder damage criterion and alloy composition. The list of models is non-exhaustive.

of days. An accelerated test that is carried to failure can stretch over several months, sometimes over a year.

Modeling and testing serve as complementary techniques. Test data are required for model validation and/or calibration, especially for new packages and assembly technologies. A reliable life prediction model is also of use in the design of experiments. Upfront simulation assists in guiding the selection of critical parameters when designing a test vehicle or planning an accelerated life test. For instance, different pad sizes can be selected for a BGA package and its test board. Solder joint life predictions for different temperature profiles can also help optimize test conditions and reduce the duration of an ATC test. For example, a combined test and modeling program was run by an industry consortium that showed that thermal cycling of SAC305 plastic ball grid array (PBGA) assemblies with dwell times of 10 or 60 min leads to similar failure modes and that failure times for short and long dwell conditions could be related to strain energy-based AFs. ${ }^{8}$ The cycle with 10-min dwells was found to be more effective because stress relaxation is fastest at the beginning of the dwell periods and then rapidly slows down. In, ${ }^{8}$ 10-min dwells provided for $50 \%$ stress relaxation and made for a more efficient test profile; i.e., a test of shorter duration for that particular SAC305 PBGA assembly. Long dwell cycles may be required for other applications and are also of use to test and validate reliability models for new $\mathrm{Pb}$-free alloys.

\section{TYPES OF LIFE PREDICTION MODELS}

Solder interconnect reliability modeling has been the subject of intensive studies for almost half a century ${ }^{2-4,6-8,10-26}$ (see Table I). Predicting solder joint fatigue life is a difficult problem because of the complex metallurgy and the time- and temperaturedependent mechanical behavior of soft solders, the three-dimensional nature of electronic assemblies and the statistical spread of failure times. All models have their own merits and limitations. Trade-offs between different approaches are in terms of accuracy, applicability, cost and skills required. In this section, models are grouped into four categories based on the computational resources needed to run them, from hand-held calculators to super-computers, as shown in Table I. Model development continues in industry and academia, and the examples below do not constitute an exhaustive list.

\section{Calculator and Spreadsheet Models}

Algebraic models are strain-based, Coffin-Manson $^{27}$ types of models with temperature and dwell time or frequency effects. ${ }^{1,2,10-14}$ These models are easy to use (and abuse) and can be implemented on a 
calculator or in a spreadsheet. Local CTE mismatch effects ${ }^{5}$ are not included since the global in-plane CTE mismatch had an overwhelming effect in the assemblies for which these models were developed.

One example of a calculator model is the NorrisLandzberg (NL) model ${ }^{10,11}$ which was developed for high $\mathrm{Pb}$ solder joints in bare die, flip-chip assemblies on ceramic substrates. The reliability of flip-chip solder joints, as predicted by the NL model, is supported by almost 50 years of use in IBM mainframe applications. This has led to a wide-spread interest in developing $\mathrm{NL}$ type models for Pb-free assemblies.

\section{PC-Based Models}

These are compact models where board and component deformations are accounted for by using the techniques of classical strength of materials. They account for the plastic flow and creep of solder, as well as local CTE mismatch effects and failure statistics. Structural analysis is by means of classical mechanics whereby circuit boards are treated as axisymmetric plates, discrete components are treated as beams, and leads of leaded packages are treated as curved beams. In most cases, the correlation of accelerated test data uses inelastic strain energy-obtained from the area of stress/strain hysteresis loops-as a measure of cyclic damage. Compact models are not computationally intensive and run rapidly on PCs.

Examples of PC-based models are: (1) the comprehensive surface mount reliability (CSMR) model developed at AT\&T Bell Laboratories ${ }^{15}$ (2) the fast assessment of interconnection reliability (FAIR) mode $^{16}$ developed at Hewlett-Packard; and (3) the solder reliability solutions (SRS) model $^{7}$ which accounts for creep of solder and different dwell times on the hot and cold sides of a thermal cycling profile. The CSMR approach was validated over a huge database of thermal cycling failure data for conventional surface mount technology (SMT) and PBGA assemblies. The FAIR model follows the CSMR approach, with a few improvements in the physical model, and is validated by accelerated test data from HP Labs. The CSMR and SRS models apply to near-eutectic $\mathrm{Sn}-\mathrm{Pb}$ assemblies and have been validated for a wide range of components. ${ }^{28,29}$ The hysteresis loop approach within the SRS model has been improved upon and extended to SAC387/405 soldered assemblies. ${ }^{8}$

\section{Workstation Models}

Examples of models that run on workstations are the Darveaux models ${ }^{17-22}$ and the Ford Computer Aided Interconnect Reliability system. ${ }^{30}$ Workstation computational power is needed for 3D nonlinear, temperature- and time-dependent FEA. ${ }^{25,26}$ In the Darveaux models, solder joint life is predicted using strain energy-based statistical crack initiation and crack growth correlations that have been validated over a wide range of components and assembly technologies.

\section{Supercomputer Models}

3D models intended to capture the intricate details of solder microstructural evolution, crack initiation and crack growth have been developed. ${ }^{3}$ Specialized, proprietary FEA codes are used and the size and complexity of the models require supercomputer resources. Model runs, up to crack initiation, may take as much as 1 week of computation. These sophisticated models are valuable research tools that may facilitate the up-front simulation of the fatigue behavior of new solder alloys.

\section{ALGEBRAIC, PLASTIC STRAIN RANGE MODELS: EXAMPLES}

Algebraic life-prediction models are popular because of their ease of use on calculators or in spreadsheets. In general, algebraic models are highly empirical. They serve their purpose well for the specific components and assembly technologies for which they were developed. However, care should be exercised when applying these models beyond their original intended use.

\section{Norris-Landzberg (NL) Model}

The NL model ${ }^{10,11}$ was developed at IBM to predict the solder joint reliability of controlled collapse chip connections (C4), i.e., solder joints in bare die assemblies using high-Pb solder $(95 \mathrm{~Pb} 5 \mathrm{Sn}$ or $97 \mathrm{~Pb} 3 \mathrm{Sn})$. The model gives the number $N$ of power on/off cycles to failure as:

$$
N=C \cdot\left[\Delta \gamma_{\max }\right]^{-1.9} f^{1 / 3} \exp \left(\frac{1450}{T_{\max }}\right)
$$

where $C$ is a material constant, $f$ is the thermal cycling frequency, $T_{\max }$ is the maximum operating temperature (in ${ }^{\circ} \mathrm{K}$ ) and $\Delta \gamma_{\max }$ is the solder joint maximum cyclic shear strain as given by Eq. 1 . The NL model is a modified Coffin-Manson ${ }^{27}$ relationship with a frequency term and an Arrhenius temperature dependence. The NL model was validated for silicon chips on alumina substrates. Conditions for its use were specified in Refs. 10, 11 and other IBM publications: (1) the model applies exclusively to $\mathrm{C} 4$ joints with high $\mathrm{Pb}$ contents; to the authors' knowledge, the applicability of the original NL model has not been demonstrated for neareutectic $\mathrm{SnPb}$; (2) beyond the temperature range 0 $100^{\circ} \mathrm{C}$, the model can only be used for rough estimates of attachment reliability; (3) the model has a frequency threshold in the range of 6-24 cycles/day; and (4) application of the NL model to underfilled flip-chip assemblies is not valid.

Since the material constant $C$ was not specified, the NL model is mostly used to derive acceleration factors. When accelerated testing has been carried to failure and a failure distribution is available for a particular assembly, the constant $C$ can be treated as a model calibration factor to fit the model to available test results. The reader is referred to the 
landmark paper by Norris and Landzberg ${ }^{11}$ for further background on the NL model. The companion paper by Goldmann ${ }^{10}$ provides a geometric model that captures the effect of pad sizes and solder volume on the fatigue life of $\mathrm{C} 4$ joints. The NL model is predominantly used to calculate AFs-defined as the ratio of cycles to failure in the field to cycles to failure in test-in the form:

$$
\begin{aligned}
\mathrm{AF}= & \left(\frac{\Delta T_{\text {test }}}{\Delta T_{\text {field }}}\right)^{1.9} \times\left(\frac{f_{\text {field }}}{f_{\text {test }}}\right)^{1 / 3} \\
& \times \exp \left[1450\left(\frac{1}{T_{\text {max,field }}}-\frac{1}{T_{\text {max,test }}}\right)\right]
\end{aligned}
$$

where the subscripts "test" and "field" refer to test and field conditions, respectively. Extensions of the NL AF model have been developed for SAC305 assemblies. ${ }^{13,31}$ For example, the model by Pan et al. ${ }^{31}$ gives SAC305 AFs as:

$$
\begin{aligned}
\mathrm{AF}= & \left(\frac{\Delta T_{\text {test }}}{\Delta T_{\text {field }}}\right)^{2.65} \times\left(\frac{t_{\text {test }}}{t_{\text {field }}}\right)^{0.136} \\
& \times \exp \left[2185\left(\frac{1}{T_{\text {max field }}}-\frac{1}{T_{\text {max }, \text { test }}}\right)\right]
\end{aligned}
$$

where dwell times, $T_{\text {test }}$ and $T_{\text {field }}$, have been substituted for cyclic frequencies under test and field conditions. Pan et al. ${ }^{31}$ suggested that the constants in Eq. 4 may need to be updated as more test data become available. Pan et al. also warned that their model may not apply to harsher conditions than $0-100^{\circ} \mathrm{C}$.

Miremadi et al. ${ }^{13}$ proposed an alternate NL model for SAC305 assemblies, similar to (4) but with component-dependent constants $\mathrm{a}, \mathrm{b}$ and $\mathrm{c}$ (Table II):

$$
\begin{aligned}
\mathrm{AF}= & \left(\frac{\Delta T_{\text {test }}}{\Delta T_{\text {field }}}\right)^{a} \times\left(\frac{t_{\text {test }}}{t_{\text {field }}}\right)^{b} \\
& \times \exp \left[c\left(\frac{1}{T_{\text {max field }}}-\frac{1}{T_{\text {max,test }}}\right)\right]
\end{aligned}
$$

The constants in Table II correlate with HP internal and industry-wide data, with the goal of extending the model to harsh conditions as well as to reduce model prediction errors. The values of the constants $a, b$ and $c$ show significant variations across Table II. This is a reflection of AFs being board- and component-dependent. The development of the above SAC305 AFs captures the results of large accelerated testing programs and huge data analysis efforts, the likes of which, to the authors' knowledge, have not been conducted for other main stream alloys, e.g., SAC105, SAC205 or SnCuNi or niche-application alloys.

\section{Engelmaier/IPC Models for Leadless Assem- blies}

The life prediction model in the IPC-SM785 standard $^{2}$ is based on Engelmaier's model for leadless ceramic chip carrier (LCCC) assemblies. ${ }^{12}$ For leadless assemblies, the median cyclic life, or cycles to $50 \%$ failures under thermal or power cycling conditions, is given as:

$$
N_{f}(50 \%)=\frac{1}{2}\left[\frac{F \Delta \gamma_{\max }}{2 \varepsilon_{f}}\right]^{\frac{1}{c}}
$$

where $\varepsilon_{f}$ is a fatigue ductility coefficient $\left(2 \varepsilon_{f}=0.65\right.$

\begin{tabular}{|c|c|c|c|c|}
\hline $\begin{array}{l}\text { Printed circuit } \\
\text { assembly(PCA)/ } \\
\text { test sub-group \# }\end{array}$ & Sub-group description: component type/ATC conditions & $a$ & $\boldsymbol{b}$ & $\boldsymbol{c}$ \\
\hline 1 & Flip-chip on board/Cond. 1 and 2 & 2.15 & 0.063 & 1211 \\
\hline 2 & PBGA, FlexBGA, QFN/Cond. 1 and 2 & 1.26 & 0.02 & 3503 \\
\hline 3 & CSP/Cond. 1 and 2 & 2.86 & 0.077 & 4532 \\
\hline 4 & LCCC, CBGA/Cond. 1 & 1.07 & 0.18 & 4286 \\
\hline 5 & HiTCE CBGA/Cond. 1 & 2.54 & 0.088 & 1972 \\
\hline 6 & LCCC/Cond. 2 & 1.92 & 0.12 & 5.9 \\
\hline 7 & TSOP, TQFP/Cond. 1 and 2 & 2.14 & 0.21 & 273.6 \\
\hline 8 & Ceramic small outline package/Cond. 2 & 0.66 & 0.087 & 2718 \\
\hline 9 & Chip resistors, capacitors/Cond. 1 and 2 & 2.19 & 0.16 & 980 \\
\hline 10 & All PCAs and ATC conditions & 1.84 & 0.11 & 2167 \\
\hline
\end{tabular}
for $60 \mathrm{Sn} 40 \mathrm{~Pb}), \Delta \gamma_{\max }$ is the maximum cyclic shear strain, as defined in Eq. 1 , and $F$ is an empirical factor. In the absence of model calibration data, $F$ is taken equal to 1 . The fatigue ductility exponent $c$ is given as:

Table II. Component-dependent constants a, b and $c$ in Miremadi et al.'s model, ${ }^{13}$ Eq. 5 
$c=-0.442-6 \times 10^{-4} T_{\mathrm{SJ}}+1.74 \times 10^{-2} \ln \left(1+\frac{360}{t_{\mathrm{D}}}\right)$

where $T_{\mathrm{SJ}}$ is the mean cyclic solder joint temperature $\left({ }^{\circ} \mathrm{C}\right)$. Under thermal cycling conditions, $T_{\mathrm{SJ}}$ is the mean of the temperature extremes $T_{\min }$ and $T_{\text {max }}$ :

$$
T_{\mathrm{SJ}}=\frac{T_{\min }+T_{\max }}{2}
$$

The parameter $t_{\mathrm{D}}$ is the half-cycle dwell time in minutes. Note that IPC-SM-785 does not specify how to handle thermal cycles with different dwell times on the hot and cold sides of the cycle. Some conditions to remember when applying the IPC model are: (1) Eq. 6 was developed by curve-fitting isothermal mechanical fatigue data for $63 \mathrm{Sn} 37 \mathrm{~Pb}$ lap joints in shear, with shear strains in the range 2-20\%, strain levels that are considered high for surface mount solder joints under use conditions; (2) the mechanical tests were conducted at $25^{\circ} \mathrm{C}$ and $100^{\circ} \mathrm{C}$ with test frequencies of 4 cycles $/ \mathrm{h}$ and 300 cycles/h, frequencies that are high compared to typical use conditions; (3) the model was validated with eight data points for LCCC assemblies under thermal or power cycling conditions; ${ }^{12,32}$ and (4) the LCCC validation data ${ }^{32}$ covered maximum cyclic shear strains from $1 \%$ to $10 \%$.

Plastic strain range models are technology-specific and should not be used blindly for all component types or beyond their intended realm of application. IPC-SM-785 lists important caveats of the model. Life predictions obtained by using the IPC-SM-785 model ${ }^{2}$ have been found at a departure from ATC test results, as discussed in Refs. 15, 16, 33 .

A Pb-free version of the Engelmaier model has been proposed for SAC305/405 leadless assemblies. ${ }^{14}$ The corresponding model constants are: $2 \varepsilon_{f}=0.48$ and:

$c=-0.390-9.3 \times 10^{-4} T_{\mathrm{SJ}}+1.92 \times 10^{-2} \ln \left(1+\frac{100}{t_{\mathrm{D}}}\right)$

The SAC305/405 constants are based on test data obtained at the University of Maryland. ${ }^{33}$ Based on our investigation, an independent validation of the SAC305/405 version of the Engelmaier model or extensions of the model to other $\mathrm{Pb}$-free solder compositions is not readily available.

\section{PC-BASED COMPACT STRAIN ENERGY MODELS}

Compact strain energy models run on PCs and use cyclic strain energy density as a solder joint damage metric. ${ }^{7,8,15,29}$ Board and component deformations are handled through strength of materials, thus minimizing computational efforts. These models account for the effect of design parameters and material properties as illustrated in Figs. 1 and 2. However, they do not capture the influence of finer geometric features such as pad design (solder mask versus non-solder mask defined pads) or solder joint voids, which are better handled by FEA. Strain energy density is obtained as the area of stress/strain hysteresis loops that capture elastic deformations, plastic flow and creep of solder. The compact strain energy models were developed for $\mathrm{SnPb}$ surface mount assemblies ${ }^{7}$ and have been extended to SAC387/405 assemblies. ${ }^{6,8}$ So far, their applicability to other solder compositions has not been demonstrated because of a lack of documented test data. Compact strain energy models have also been used to predict the fatigue life of insulatedgate bipolar transistor solder layers in high-power modules that experience rapid on and off cycles. ${ }^{34-36}$

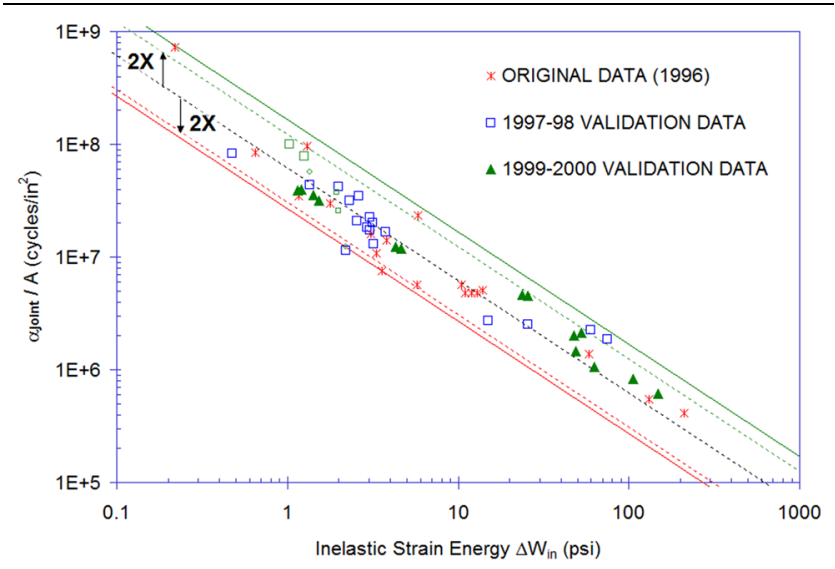

Fig. 3. Correlation of $\mathrm{SnPb}$ solder joint fatigue data over three orders of magnitude: cycles to failure (characteristic life, $\alpha_{\text {joint }}$ ) scaled for the solder crack area, $A$, versus cyclic inelastic strain energy density, $\Delta W_{\text {in. }}$ Reprinted with permission from Ref. 29.

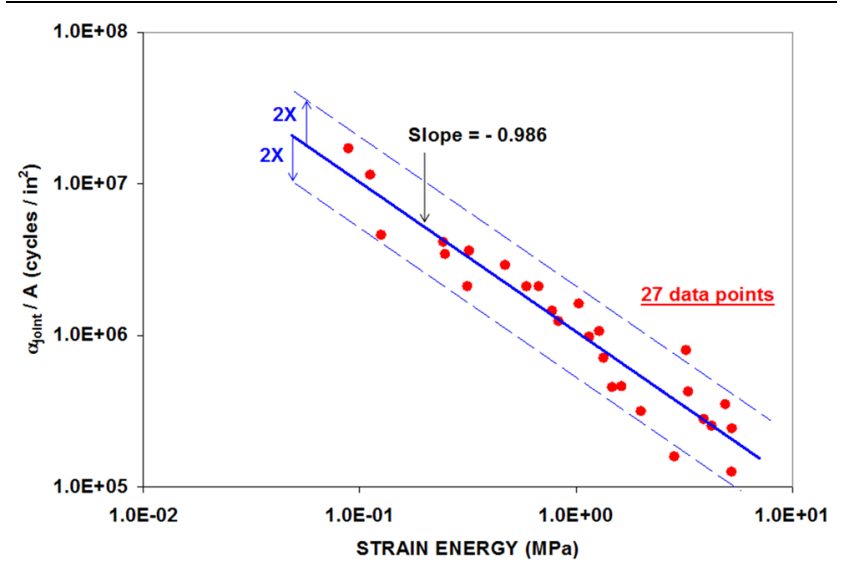

Fig. 4. Correlation of SAC387/405 solder joint thermal fatigue data over two orders of magnitude: cycles to failure (characteristic life) scaled for the solder crack area, $A$, versus cyclic strain energy density. Reprinted with permission from Ref. 8 
Figures 3 and 4 show correlations of solder joint characteristic lives scaled for solder joint crack or load bearing areas, A, for $\mathrm{SnPb}$ and SAC387/405 assemblies, respectively, versus cyclic strain energy. Cycles-to-failure per unit area on the vertical axis serve as a scaled measure of cyclic life. The inverse parameter (crack area per cycle) is the twodimensional equivalent of fatigue crack propagation rates in units of crack length per cycle. In other words, the solder crack area, which varies by over one order of magnitude with packaging technology and assembly pitch, serves as a life scaling factor (the solder joint lifetime is divided by the solder crack area). In both cases, $\mathrm{SnPb}$ and SAC, the slope of the best-fit lines through the data points of Figs. 3 and 4 is close to -1 , which justifies using ratios of cyclic strain energies under test and field conditions to obtain AFs. In the $\mathrm{SnPb}$ case (Fig. 3), the initial centerline correlation was based on the results of 19 independent experiments. The data fall within lower and upper bounds that are a factor of 2.3-2.7 times from the model centerline. The correlation band was validated over time for a total of over 60 data points as seen in Fig. 3. Each data point represents a single experiment with welldocumented geometry, board and component material properties. In the case of SAC assemblies (Fig. 4), the correlation of test data covers two orders of magnitude in life. It is important that model correlations cover a wide range of cyclic lives since test failures may occur in a few hundreds to a few thousand cycles, whereas product lives may cover tens of thousands of cycles. That is, test data correlations should cover the low strain energy areas that are experienced by board assemblies in service.

When running simulations with compact models, data entries include the 14 parameters that were described earlier regarding Fig. 1. Another 24 package parameters are also entered for plastic BGA and CSP assemblies ("thickness of each layer + three material properties each" times six layers), as discussed with respect to Fig. 2a. Assuming that a particular model applies to a given situation, simulation results are only as good as the input data that are fed into the models. Measurements of material properties often are needed as handbook values may not apply to the product at hand and may not reflect changes in material formulations, especially in the case of printed wiring boards, molding compounds and other plastic materials.

Creep, the time- and temperature-dependent deformation of a solder specimen under a given load, is the dominant deformation mode of soft solders. Creep mechanisms contribute to irreversible deformations and cumulative damage within the solder joints. The availability of creep data and the choice of an adequate creep constitutive model are crucial to the development of compact solder joint life models as well as finite-element life data correlations. One way of validating the choice of a creep constitutive model is to simulate solder joint stress/strain hysteresis loops that have been measured during temperature cycling. Figure 5a and $\mathrm{b}$ shows measured stress/strain data and simulations for $\mathrm{SnPb}$ and SAC305 assemblies. ${ }^{6,8}$ These loops illustrate the complexity of the solder joint stress/strain response during thermal cycling. In the $\mathrm{SnPb}$ case, the constitutive model includes temperature-dependent instantaneous plastic flow and steady state creep. $\mathrm{SnPb}$ hysteresis loop data were first obtained by Hall. ${ }^{37-39}$ In the SAC305 case, the constitutive model only includes temperaturedependent steady-state creep. The stress/strain measurements in Ref. 40 were obtained by analysis of digital speckle correlation data. Note that the shear stress near the beginning of the hot dwell period at $125^{\circ} \mathrm{C}$ is slightly higher, in absolute value, than the shear stress on the cold side of the cycle at $27^{\circ} \mathrm{C}$ (Fig. 5b). This is unexpected since creep rates decrease as temperature goes up. As valuable as they are, few hysteresis loops have been measured for new Pb-free alloy assemblies.

Hysteresis loops provide useful information for solder joint reliability analysis. The width of the loop gives an estimate of the cyclic inelastic strain range that solder joints experience. The inelastic strain range is used in Coffin-Manson type of fatigue laws. The hysteresis loop area is a measure of the amount of cyclic strain energy that is imparted to solder joints. Strain energy is used in Morrow's type of fatigue laws ${ }^{41}$ where cycles to failure are given as a function of the cyclic inelastic strain energy density, $\Delta W_{\text {in }}$ :

$$
N_{f}=\frac{C^{\prime}}{\Delta W_{\text {in }}^{n}}
$$

$C^{\prime}$ is a material constant and the exponent $\mathrm{n}$ is in the range of 0.7-1.6 for several engineering metals, including soft solders. For standard $\mathrm{SnPb}$ and SAC387/396/405 surface mount assemblies, it has been reported that the exponent $\mathrm{n}$ is very close to 1 . Refs. 7, 8. A similar relationship was first proposed for thermal cycling of solders ${ }^{42}$ based on the application of dislocation theory to generic solder fatigue models. An inverse relationship between thermal cycling life and strain energy was also arrived at in Refs. 23, 24 using a combination of fracture mechanics theory, Miner's rule cumulative damage $^{43}$ and a creep rupture criterion. AFs are thus obtained as the ratio of cyclic strain energy densities $(\Delta W)$ under test and field conditions:

$$
\mathrm{AF} \equiv \frac{N_{f}(\text { field })}{N_{f}(\text { test })}=\frac{\Delta W(\text { test })}{\Delta W(\text { field })}
$$

where $N_{f}$ is cycles to failure and $\Delta W$ is cyclic strain energy density under test and field conditions. 


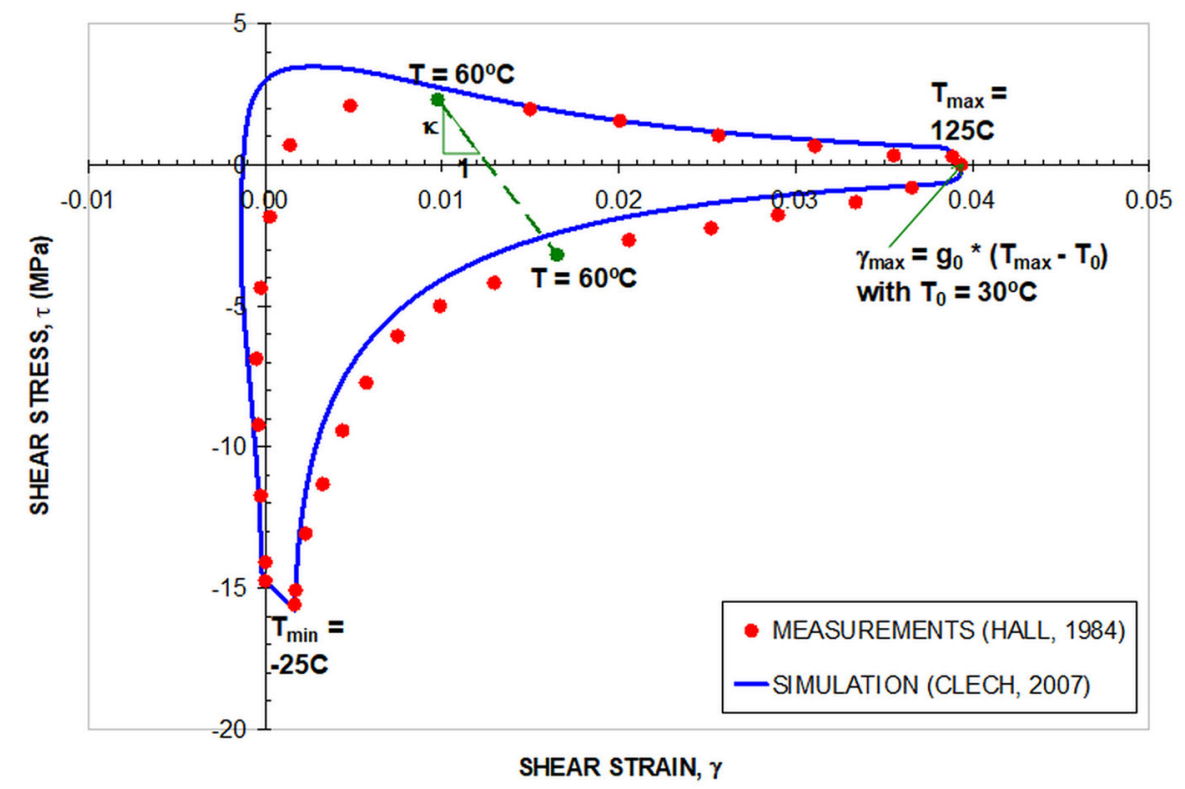

(a)

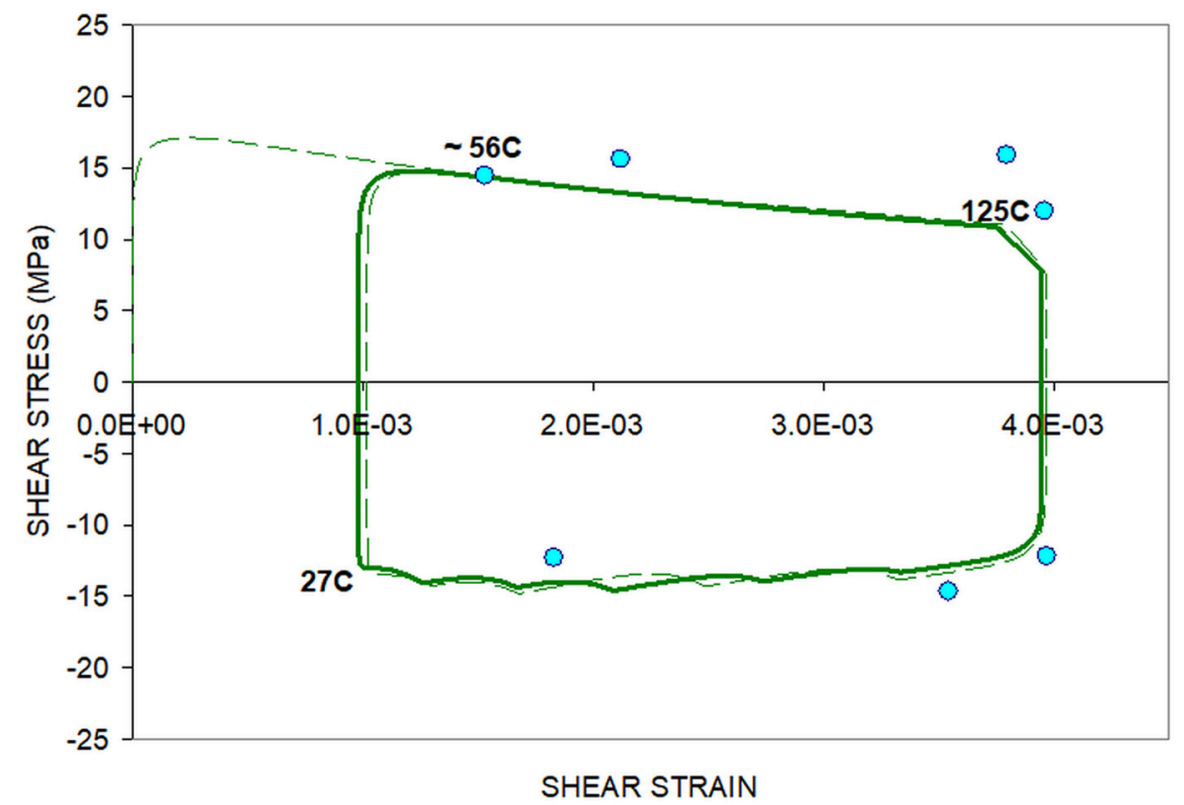

(b)

Fig. 5. (a) SnPb stress/strain loop simulation for $84 \mathrm{l} / \mathrm{O}$ LCCC on FR-4 during thermal cycling between $-25^{\circ} \mathrm{C}$ and $125^{\circ} \mathrm{C}$, with slow ramps $\left(0.5^{\circ} \mathrm{C} / \mathrm{min}\right)$ and long dwell times $(2 \mathrm{~h})$. Data points are from Hall's measurements. ${ }^{37} g_{0}=\left(L / h_{\mathrm{S}}\right) \times \Delta \alpha$ is the maximum shear strain range per degree of temperature rise, where $\Delta \alpha$ is the board to component CTE mismatch. (b) SAC305 stress/strain loop simulation for flip-chip BGA assembly thermally cycled between $27^{\circ} \mathrm{C}$ and $125^{\circ} \mathrm{C}$. SAC305 data points are from Ref. 40 . Reprinted with permission from Ref. 6.

The steady state creep rate, $\stackrel{\circ}{\varepsilon_{\mathrm{SS}}}$, that is used to simulate hysteresis loops, is given in its simplest form as a function of stress, $\sigma$, and the absolute temperature, $T$ :

$$
\stackrel{\circ}{\varepsilon_{\mathrm{SS}}}=B \cdot g^{-p} \cdot \sigma^{n} \exp \left(-\frac{Q_{a}}{k T}\right)
$$

where $B$ is a material constant, $g$ is the initial material grain size, $k$ is Boltzman's constant, the exponents $\mathrm{p}$ and $\mathrm{n}$ are constants, and $Q_{a}$ is the apparent activation energy of the rate controlling mechanism. Equation 12, which is a simplified version of Dorn's equation, ${ }^{44}$ shows the strong 
dependence of creep rates on stress and temperature as well as grain size. The stress dependence is not necessarily in the form of a single power law, it is sometimes given as the sum of two power laws or a hyperbolic sine ("sinh") function. The grain size dependence is a significant microstructural effect. The latter effects are much more complex in the case of SAC solders since these alloys are dispersion-strengthened alloys where deformation and failure mechanisms depend on average precipitate sizes and their spacing across sub-grains. ${ }^{45-48}$

Creep properties also vary with specimen size, particularly in the case of SAC solder joints. ${ }^{45,47}$ The mechanical response of small solder joints thus differs from that of bulk solder test specimens. For engineering purposes, it is thus preferable to use a constitutive model developed from measurements on real solder joint specimens. Techniques have been developed to measure solder creep on solder joints of actual $\mathrm{SnPb}$ and $\mathrm{Pb}$-free assemblies, e.g., Refs.18, 22, 49, 50.

\section{WORKSTATION-BASED FEA}

FEA is a powerful numerical technique that is commonly used to solve structural analysis problems. The geometry of the structure of interest is divided into small elements of known mechanical behavior. Elements have nodes that represent discrete points of the structure. The model is subject to boundary conditions that represent the physical constraints of the structure. FEA provides for an approximate solution of nodal displacements under applied mechanical or thermal loads. The displacement solution is then used to determine strains and stresses anywhere in the structure. The geometrical model, the finite element mesh, the boundary conditions, material properties, applied loads and the analysis type are defined in a pre-processor. A computational engine solves for nodal displacements, stresses and strains. A post-processor provides output results such as deformation plots, stress, strain and strain energy tables or contour plots. While commercial software has streamlined the FEA process, care must be exercised in both the pre- and post-processing phases. For example, FEA results are sensitive to element type and mesh refinement. A coarse mesh provides for savings in computational time. However, a finer mesh is required in areas with high stress gradients or across material interfaces. Similarly, the number of loading steps and the size of time steps lead to a trade-off between computational time and accuracy of the results. ${ }^{19-21}$

When applied to SMT assemblies, FEA provides strain energy density results that can be related to solder joint lifetimes. ${ }^{17-24}$ The analysis needs be set up carefully since creep of solder is a time-dependent problem. The usual element size effects are compounded by stress-singularities arising in elements at or near the edges of solder joint interfaces. Although the FEA method has been automated, the above issues call for the engineering judgment of a skilled analyst before the method can be applied routinely. Depending on the size of the model (i.e., the number of nodes and elements), FEA runs that include creep of solder take a few hours of CPU time on common workstations. Full three-dimensional models of soldered assemblies are the most representative of the structure being analyzed, but the large number of nodes and elements involved make the models computationally intensive. The size of the models can be reduced by taking advantage of symmetries ("one-fourth" or "oneeighth" models) or by modeling a sub-section ("slice" models) of the structure under consideration.

Guidelines for the use of FEA to predict solder joint life have been documented in detail by Darveaux. ${ }^{17,22}$ The Darveaux approach for $\mathrm{SnPb}$ and $\mathrm{Pb}$-free assemblies correlates crack initiation cycles, $\mathrm{N}_{\mathrm{i}}$, and crack growth rate, $\mathrm{da} / \mathrm{dN}$, to an average strain energy density $\Delta W_{\text {ave }}$ :

$$
\begin{aligned}
N_{i} & =C_{3} \Delta W_{\mathrm{ave}}^{C_{4}} \\
\frac{\mathrm{d} a}{\mathrm{~d} N} & =C_{5} \Delta W_{\mathrm{ave}}^{C_{6}}
\end{aligned}
$$

where $C_{3}, C_{4}, C_{5}$ and $C_{6}$ are solder material constants.

The $C_{4}$ and $C_{6}$ exponents are rather independent of element thickness along the critical solder joint interface and have average values: $C_{4}=1.43$, $C_{6}=1.14$ for standard $\mathrm{SnPb}$ assemblies ${ }^{19}$ However, the $C_{3}$ and $C_{5}$ constants vary with element thickness. In order to make absolute life predictions, the appropriate model constants must be used, consistent with the minimum element size for which the correlations ${ }^{19,21}$ were developed. The "element size/model constants" problem is not as much of an issue when using the model to determine acceleration factors since the exponents $C_{4}$ and $C_{6}$ are less mesh sensitive. Stress/strain singularity effects and the impact of element size on solder joint strain energy density are recognized as potential hurdles to the use of the FEA approach. Singularity refers to the fact that strain energy density keeps increasing when a finer and finer mesh is used in critical solder joint areas. Singularity effects occur at sharp corners and at the edge of bi-material interfaces, a numerical problem that is inherent to most commercial FEA codes. These issues lead to the following recommendations ${ }^{19}:$ (1) keep the element size consistent from one model to the next; and (2) instead of using maximum values of the strain energy density, as obtained in the critical solder joint areas, use a volume-averaged strain energy density:

$$
\Delta W_{\mathrm{ave}}=\frac{\sum \Delta W \cdot V}{\sum V}
$$

where $V$ is the volume of an individual element and $\Delta W$ is the viscoplastic strain energy density accumulated per cycle in that element. The volume- 


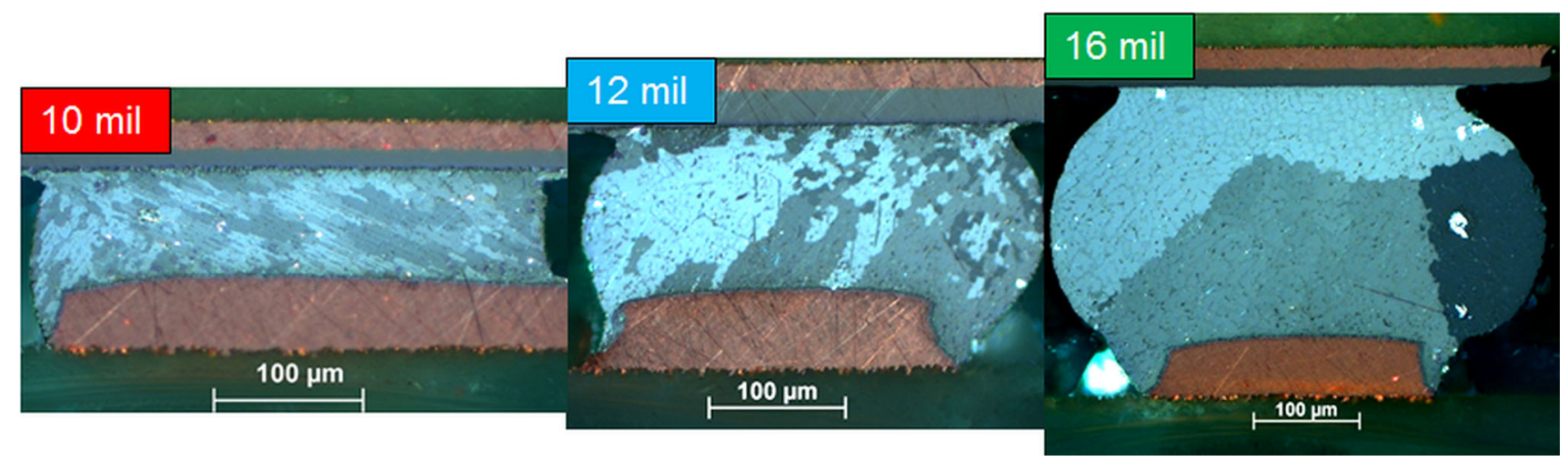

Fig. 6. Optical micrographs with cross polarizers of SAC 305 assemblies with different solder volumes. 10-mL samples show the presence of interlaced twinned morphology whereas $16-\mathrm{mL}$ samples show beach-ball structure. Reprinted with permission from Ref. 64.

averaging is done along the first layer of elements along the solder joint interface where fatigue cracks are expected to propagate.

Darveaux's FEA approach to solder joint life predictions has been validated for $\mathrm{SnPb}$ assemblies across a large database with over 100 experiments covering a variety of SMT packages and test conditions. The model constants in Eqs. 13 and 14 have been updated for SAC305, SAC405, Sn3.5Ag, $\mathrm{Sn} 0.7 \mathrm{Cu}$ and $\mathrm{Sn} 1.2 \mathrm{Ag} 0.5 \mathrm{Cu} 0.05 \mathrm{Ni}^{22}$ but with much less test data available than for $\mathrm{SnPb}$.

\section{SHORTCOMINGS IN MODELING: MICROSTRUCTURE, PROPERTIES AND FAILURE MECHANISMS OF SOLDER JOINTS}

There are significant challenges in developing a fundamental understanding of the relationship between microstructure, constitutive properties, and the thermomechanical failure mechanism of SAC solder during thermal cycling. These challenges make it difficult to correlate test data and validate models and consequently, predict the failure process.

The microstructures of eutectic $\mathrm{SnPb}$ and $\mathrm{Pb}$-free solder joints are quite different. Multiple publications have shown differences in their initial microstructure, their evolution under stress and temperature, and their failure mechanisms. $46,51-55$ In the case of SAC solder joints, a complex relationship between thermal history, alloying elements, undercooling and growth behavior results in an intricate, multi-phase microstructure after reflow with significant challenges for analysis after assembly, and after thermomechanical testing. Several publications have shown that each aspect of microstructure such as size and distribution of precipitates in the Sn matrix, Sn dendrite arm size and spacing, Sn grain numbers and orientations, and intermetallic compounds at interfaces, could significantly affect the reliability of $\mathrm{Pb}$-free solder joints in service. ${ }^{46,55-61}$
The thermomechanical properties of SAC solder joints are also known to be very dependent on the size or volume of the joint. Smaller joints undercool more and exhibit a larger number of smaller-sized precipitates. ${ }^{45,61}$ In addition, there is variation in the distribution of precipitates and size of $\mathrm{Sn}$ dendrites across the joint. In the region closer to the nucleation point, the Sn dendrites are smaller and smaller precipitates can be detected. ${ }^{45,60}$ This becomes more complex as the nucleation point is affected by the substrate morphology and composition. ${ }^{58-63}$ The Sn grain morphology of SAC joints also varies as the solder volume changes; smaller joints often show interlaced Sn grain morphology while larger joints solidify at higher temperatures and show beach ball Sn grain morphology (Fig. 6). These variations of microstructure as a function of solder volume directly affect the thermomechanical properties of the solder joint such as creep and fatigue and thus reliability. The results of one study showed direct correlation between Sn grain morphology and lifetime in a thermal cycling test. ${ }^{64}$ SAC land grid array assemblies that displayed an interlaced Sn grain structure exhibited a significantly longer lifetime as compared to the lifetime of BGA packages with the beach-ball $\mathrm{Sn}$ grain morphology. ${ }^{64}$

The microstructural evolution of $\mathrm{SnPb}$ and $\mathrm{SAC}$ solder during ATC tests are also significantly different. As reported before, precipitate coarsening and creep properties change dramatically for SAC solder joints over time. ${ }^{65,66}$ Thermal fatigue cracks in $\mathrm{SnPb}$ and $\mathrm{SAC}$ solders typically propagate through the bulk solder. When viewed in crosssection at low magnification, the cracking in both types of solders can appear to be similar. However, closer examination shows significant differences in their respective microstructures, fractures and crack propagation characteristics. In $\mathrm{SnPb}$ solder, cracking is preceded by heterogeneous grain coarsening, a type of grain growth induced by the combination of strain and thermal exposure during 


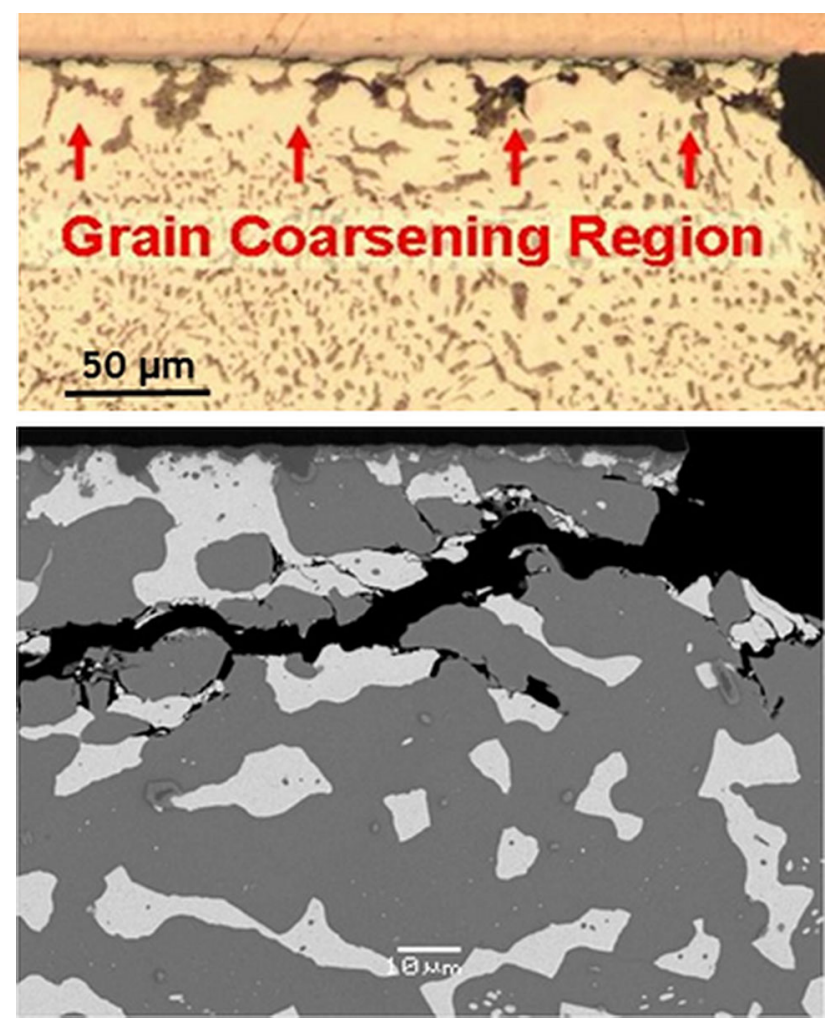

Fig. 7. Optical and scanning electron micrographs showing thermal fatigue crack in $\mathrm{SnPb}$ solder joints. Full crack occurs on the component side.

temperature cycling. After the fatigue crack initiates, it propagates across the solder joint often along the boundaries between the Sn-rich and Pb-rich phases. Figure 7 illustrates the grain coarsening phenomenon and the fatigue crack propagation in a $\mathrm{SnPb}$ area array solder.

Compared to Sn-Pb solder, SAC solders undergo a more complex microstructural evolution during temperature cycling that is more difficult to monitor and characterize. SAC fractures not only are markedly different from those of $\mathrm{SnPb}$ but can vary significantly in appearance from sample to sample. Generally, in the case of SAC solder joints, strainenhanced precipitate coarsening and recrystallization occurs in certain regions of the joint (Fig. 8a) followed by global recrystallization across the high strain region (Fig. 8b). A fatigue crack then propagates along the network of grain boundaries through the recrystallized area until failure (Fig. 8c). A continuous network of high-angle boundaries was observed to provide a path for fatigue cracks to propagate. ${ }^{64,66-68}$ The recrystallization behavior in SAC solder joint was first reported by Dunford and further investigated by other researchers. ${ }^{68-71}$

Further work is required to understand the failure mechanism of SAC solder joints in thermal cycling tests. Sn is a complicated metal and its deformation mechanism is not clearly understood.
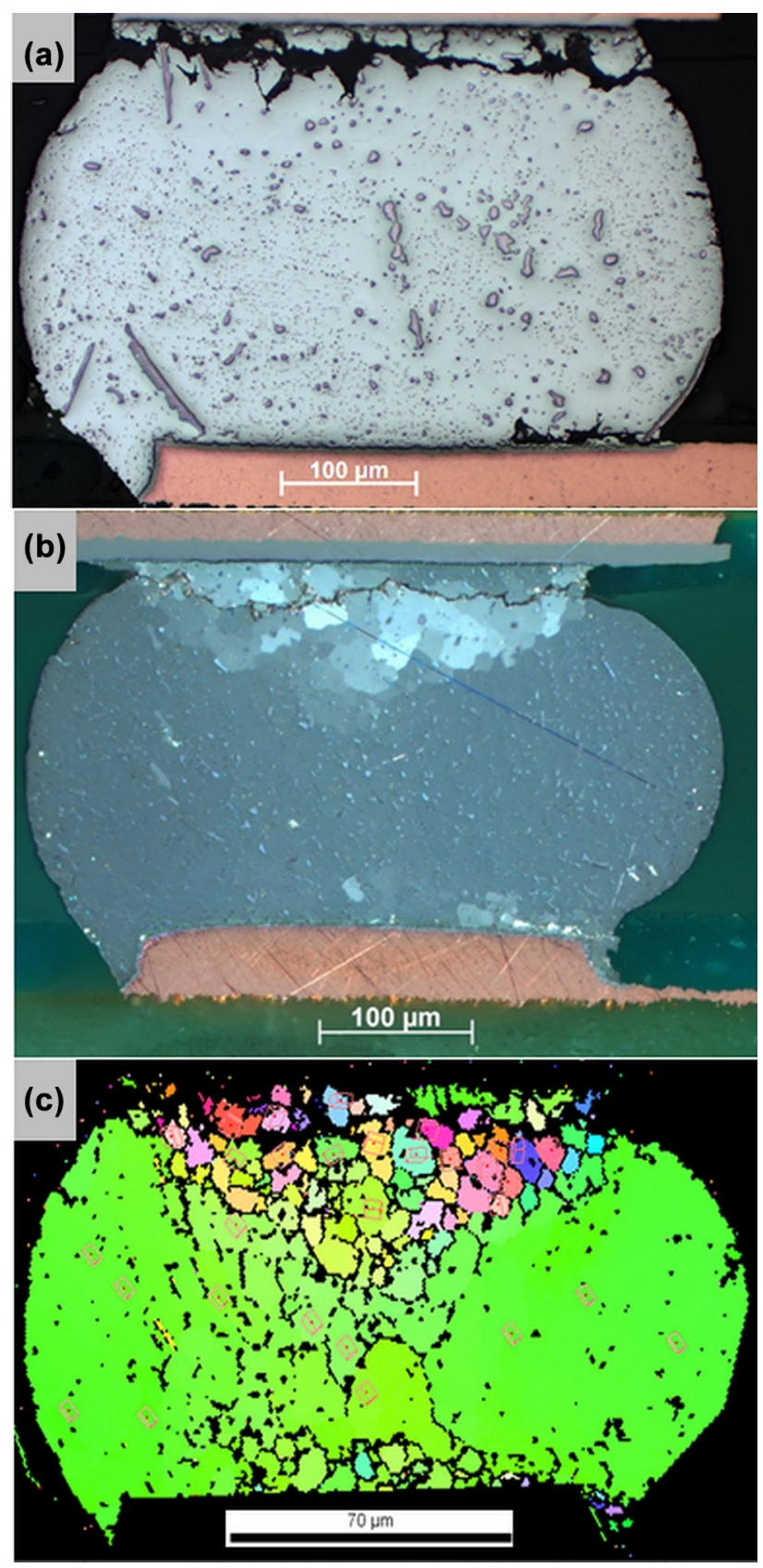

Fig. 8. Optical micrographs of a 16-mL SAC 305 solder joint failed after $0 / 100^{\circ} \mathrm{C}$ thermal cycling. (a) Strain-enhanced coarsening close to crack area; larger and fewer precipitates are evident. (b) Crosspolarized image of a joint showing global recrystallization. (c) The EBSD map from the joint in (b) indicates that the crack pathway was between recrystallized $\mathrm{Sn}$ grains of distinctly different orientations. Reprinted with permission from Ref. 67.

There are more slip systems in Sn than in most metals, revealing the intricacy of plastic deformation of $\mathrm{Sn}$ and of $\mathrm{Pb}$-free solders. ${ }^{72,73}$ Performing transmission electron microscopy analysis is extremely challenging as $\mathrm{Sn}$ is a soft metal and sample preparation is difficult, limiting knowledge of the 
nature of dislocations and their interaction with precipitates. Analyzing various aspects of microstructure of $\mathrm{Pb}$ free interconnects and their evolution becomes more challenging for the new generation of $\mathrm{Pb}$-free solders that contain alloying elements such as $\mathrm{Bi}, \mathrm{Sb}$, and $\mathrm{In}$. Those elements promote solid solution hardening to supplement the precipitate strengthening of $\mathrm{SnAgCu}$ alloys. ${ }^{46,67}$ Understanding the thermomechanical properties of these 4-6 element solder alloys and developing microstructurally constitutive models for them presents a major challenge to develop reliable models to predict solder joint life.

\section{FUTURE MODEL DEVELOPMENT GUIDELINES AND CHALLENGES}

Based on past experience, ${ }^{6-8,13,15,18-24}$ it takes at least 12-24 datasets and a variety of component types to develop a reliable life-prediction model. The following guidelines may be of help for the development of reliability models for existing and new solder alloy compositions. First, the model correlation datasets should cover two to three orders of magnitude in fatigue lives. Second, the data should come from test vehicles with a variety of components and substrates with different thickness, materials and CTEs. Board and component material properties need be measured or estimated accurately to develop a valid correlation of lifetime test data. A suggested, non-exhaustive list of common components for reliability modeling includes: leadless conventional SMT components (LCCC, chip resistors and capacitors), leaded components (PLCC, PQFP, SOT/SODs, Alloy42 and copper TSOPs), BGAs (PBGAs, full and perimeter arrays with different die sizes, SBGAs, CBGAs), flip-chip components, with and without underfill, CSPs and fine-pitch area-arrays ( $\mu \mathrm{BGA}$, flexBGA, other finepitch BGAs, SON/BLP, QFNs). Third, test conditions should cover a wide range of temperature profiles with small and large temperature swings, and long and short dwell times. Finally, once the curve-fitting constants of an empirical model have been determined, the model should be validated against independent test data.

Considerable effort has been expended to assess the reliability of $\mathrm{Pb}$-free assemblies. The general approach has been rank-ordering of alloys under ATC conditions; however, rank-ordering may change when going from harsh to mild conditions or from short to long dwell periods. ${ }^{8,74}$ The rankordering of alloys is also affected by the mechanical and physical properties of package materials when $\mathrm{SnPb}$ and $\mathrm{Pb}$-free versions of plastic packages use different molding compounds, die attach, solder mask or substrate materials. AFs and predictive life models help resolve these conundrums by providing the means to extrapolate test failure times to use conditions. Emphasis in model development has been placed on the high-Ag, main stream alloys, e.g., SAC396, SAC387 and SAC305; however, in practice, mixed alloy assemblies occur using solder balls and solder paste of different compositions, resulting in solder joints with a different average composition. There is thus a need to develop composition-dependent life models. An attempt at extrapolating thermal cycling lifetimes within the SAC family of alloys was presented in Ref. 6.

Similarly, niche-application solders have received little attention from model developers. Modeling techniques that were discussed earlier can be of use to derive AFs for these solder alloys, if appropriate, constitutive models are available. Solder alloy proliferation also provides an opportunity to develop "smarter" models, i.e., creep and predictive life models based on first-principles, ${ }^{75}$ since it would be cost-prohibitive to gather large empirical databases, comparable to what was done for neareutectic $\mathrm{SnPb}$, for each $\mathrm{Pb}$-free alloy. ${ }^{76}$

While the microstructure of $\mathrm{SnPb}$ joints display many Sn-rich and $\mathrm{Pb}$-rich regions due to eutectic solidification, Sn-based Pb-free alloys such as SAC305 form joints that may only have one or a low number of grains. The microstructure is also volume- and process-dependent, resulting in beachball or interlaced-twinning configurations (Fig. 6) that appear to have markedly different creep properties. ${ }^{64,77}$ New constitutive and reliability models must be developed to account for these effects. Finally, thermal cycling results for Sn-based $\mathrm{Pb}$-free assemblies have demonstrated the importance of microstructural features such as precipitate size and spacing, Sn dendrites arm size and spacing, and Sn grain numbers and orientations. ${ }^{45-48}$ The effects of those parameters on solder joint life are presently unaccounted for in $\mathrm{Pb}$-free reliability models. For a given solder alloy, the microstructure is affected by the soldering process and aging conditions and continues to evolve under field or test conditions. ${ }^{78-81}$ How to capture these microstructural effects in predictive models represents a formidable task that has just begun to be addressed. ${ }^{82}$

\section{CONCLUSION}

This paper has reviewed engineering models that are currently available to predict solder joint reliability under thermal cycling conditions. Different categories of models were reviewed, examples were provided, and model limitations were discussed. Some of the models that were developed for the eutectic $\mathrm{SnPb}$ solder alloy have been extended to high-Ag, Pb-free alloys such as SAC305 and SAC405. However, models are lacking for other Pb-free solder compositions, particularly newly developed alloys with the addition of significant amounts of $\mathrm{Bi}, \mathrm{Sb}$, and $\mathrm{In}$. Those SAC alloys benefit from both precipitate- and solid solutionstrengthening mechanisms. More importantly, the majority of existing engineering models do not 
capture the effect of the initial microstructure and its evolution during thermal cycling tests. Lack of that information greatly affects the accuracy of predicted failure times of electronic packages. Significant efforts are needed across industry and academia to develop constitutive models that capture the evolving microstructural effects, such as precipitate coarsening and formation of a network of grain boundaries in high-strain regions, which ultimately result in the recrystallization-assisted cracking that is unique to $\mathrm{Pb}$-free assemblies. A detailed understanding of these microstructural interactions is crucial to developing future reliability models.

\section{REFERENCES}

1. IPC-9701A, IPC Association (Bannockburn, IL: IPC Publications, 2006).

2. IPC-SM-785, IPC Association (Bannockburn, IL: IPC Publications, 1992).

3. D.R. Frear, S.N. Burchett, M.K. Neilsen, and J.J. Stephens, Solder. Surf. Mount Technol. 25, 39 (1997).

4. D.M. Pierce, S.D. Sheppard, A.F. Fossum, P.T. Vianco, and M.K. Neilsen, J. Electron. Packag. 130, 011002-1 (2008).

5. J.P.M. Clech, F.M. Langerman, and J.A. Augis, Proceedings of the Electronic Components and Technology Conference (Las Vegas, Nevada, 1990), pp. 368-376.

6. J.P. Clech, Proceedings of the SMTA International Conference (Fort Worth, TX, 2013), pp. 293-309.

7. J.P. Clech, Proceedings of the SMTA International Conference (San Jose, CA, 1996), pp. 136-151.

8. J.P. Clech, Proceedings of the SMTA International Conference (Chicago, IL, 2005), pp. 902-918.

9. P.M. Hall, Thermal Stress and Strain in Microelectronics Packaging, ed. J.H. Lau (New-York: Van Nostrand Reinhold, 1993), p. 78.

10. L.S. Goldmann, IBM J. Res. Dev. 13, 251 (1969).

11. K.C. Norris and A.H. Landzberg, IBM J. Res. Dev. 13, 266 (1969).

12. W. Engelmaier, IEEE Trans. Compon. Hybrids Manuf. Technol. 6, 232 (1983).

13. J. Miremadi, G. Henshall, A. Allen, E. Benedetto, and M. Roesch, Proceedings of the IMAPS Conference (San Jose, CA 2009), pp. 316-323.

14. W. Engelmaier, Glob. SMT Packag. 8, 46 (2008).

15. J.P.M. Clech, J.C. Manock, D.M. Noctor, F.E. Bader, and J.A. Augis, Proceedings of the Electronic Components and Technology Conference (Orlando, FL, 1993), pp. 62-70.

16. Z. Mei, Proceedings of the Electronic Components and Technology Conference (Seattle, WA 1998), pp. 268-276.

17. R. Darveaux, Proceedings of the ISHM Conference (Dallas, TX 1993), pp. 86-97.

18. R. Darveaux, K. Banerji, A. Mawer, and G. Dody, Ball Grid Array Technology, ed. J.H. Lau (New-York: McGraw-Hill, 1995), p. 379.

19. R. Darveaux, Proceedings of the Design and Reliability of Solders and Solder Interconnections Symposium (Orlando, FL 1997), pp. 213-218.

20. R. Darveaux, Proceedings of the Electronic Components and Technology Conference (Las Vegas, NV 2000), pp. 1048-1058.

21. R. Darveaux, J. Electron. Packag. 124, 147 (2002).

22. R. Darveaux, Proceedings of the SMTA International Conference (Fort Worth, TX 2013), pp. 144-155.

23. A.R. Syed, Proceedings of the Design and Reliability of Solders and Solder Interconnections Symposium (Orlando, FL 1997), pp. 347-355.

24. A.R. Syed, Proceedings of the Electronic Components and Technology Conference (Las Vegas, NV 2004), pp. 737746.
25. A. Dasgupta, C. Oyan, D. Barker, and M. Pecht, J. Electron. Packag. 114, 152 (1992).

26. E. George, D. Das, M. Osterman, and M. Pecht, IEEE Trans. Device Mater. Reliab. 11, 328 (2011).

27. S.S. Manson, Thermal Stress and Low-Cycle Fatigue, Reprint ed. (Malabar: Robert E. Krieger Publishing Co., 1981), pp. 1-395.

28. J.-P. Clech, Proceedings of the SMTA International Conference (San Jose, CA 1998), pp. 315-324.

29. J.-P. Clech, Proceedings of the System Integration in Micro Electronics, SMT ESS \& Hybrids Conference (Nuremberg, Germany 2000), pp. 19-28.

30. Y.-H. Pao, V. Reddy, E. Jih, D.R. Liu, and W.L. Winterbottom, Proceedings of the Nepcon West Conference (Anaheim, CA 1996), pp. 1681-1690.

31. N. Pan, G.A. Henshall, F. Billaut, S. Dai, M.J. Strum, E. Benedetto, and J. Rayner, Proceedings of the SMTA International Conference (Chicago, IL 2005), pp. 876-883.

32. W. Engelmaier, Solder Joint Reliability: Theory and Applications, ed. J.H. Lau (NewYork: Van Nostrand Reinhold, 1991), pp. 545-587.

33. P. Chauhan, M. Osterman, S.W.R. Lee, and M. Pecht, IEEE Trans. Compon. Hybrids Manuf. Technol. 3, 693 (2009).

34. I.F. Kovacevic, U. Drofenik, and J.W. Kolar, Proceedings of the International Power Electronics Conference (Sapporo, Japan 2010), pp. 2106-2114.

35. I.F. Kovacevic, J.W. Kolar, and U. Shilling, Reliability of Power Electronic Converter Systems, ed. H.S-H. Chung, H. Wang, F. Blaabjerg, and M. Pecht (Stevenage, UK: Institution of Engineering and Technology, 2015), pp. 103-140.

36. $\mathrm{H}$. $\mathrm{Lu}$ and C. Bailey, Proceedings of the International Conference on Electronic Packaging Technology (2016), pp. 1059-1063.

37. P.M. Hall, IEEE Trans. Compon. Hybrids Manuf. Technol. 7, 314 (1984).

38. P.M. Hall, IEEE Trans. Compon. Hybrids Manuf. Technol. 12,556 (1987).

39. P.M. Hall, Solder Joint Reliability: Theory and Applications, ed. J.H. Lau (New-York: Van-Nostrand Reinhold, 1991), p. 306.

40. A. Shirazi, Ph. D. dissertation, Ryerson University, Toronto, Ontario, Canada, 2011.

41. J. Morrow, Internal Friction, Damping and Cyclic Plasticity, 67th Annual Meeting, American Society for Testing and Materials, Chicago, IL (Philadelphia, PA: ASTM Special Technical Publication No. 378, ASTM, June 22, 1964), pp. $45-86$.

42. J. Huang, H.Y. Lai, Y.Y. Qian, and Q.L. Wang, IEEE Trans. Compon. Hybrids Manuf. Technol. 15, 553 (1992).

43. M.A. Miner, J. Appl. Mech. 3, 159 (1945).

44. J.E. Bird, A.K. Mukherjee, and J.E. Dorn, Quantitative Relation between Properties and Microstructure, ed. D.G. Brandon and A. Rosen (Jerusalem: Israel Universities Press, 1969), pp. 255-342.

45. B. Arfaei and E. Cotts, J. Electron. Mater. 38, 2617 (2009).

46. R.J. Coyle, K. Sweatman, and B. Arfaei, J. Met. 67, 2394 (2015).

47. T.M.K. Korhonen, L. Lehman, M.A. Korhonen, and D.W. Henderson, J. Electron. Mater. 36, 173 (2007).

48. R. Coyle, R. Parker, B. Arfaei, F. Mutuku, K. Sweatman, K. Howell, S. Longgood, and E. Benedetto, Proceedings of the Electronic Components and Technology Conference (IEEE, Orlando, FL, 2014), pp. 425-440.

49. M.C. Shine and L.R. Fox, Low Cycle Fatigue (ASTM Special Technical Publication STP 942, 1987), pp. 588-610.

50. S. Knecht and L. Fox, Solder Joint Reliability: Theory and Applications, ed. J.H. Lau (New York: Van-Nostrand Reinhold, 1991), p. 508.

51. E. Bradley, C.A. Handwerker, J. Bath, R.D. Parker, and R.W. Gedney, Lead-Free Electronics (Chichester: Wiley, 2007).

52. P. Snugovsky, H. McCormick, S. Bagheri, Z. Bagheri, C. Hamilton, and M. Romansky, J. Electron. Mater. 38, 292 (2008). 
53. T. Bieler, H. Jiang, L. Lehman, T. Kirkpatrick, and E. Cotts, Proceedings of the Electronic Components and Technology Conference (San Diego, CA, 2006), pp. 14621467.

54. S.K. Kang, IBM Research Report, RC25045 (New York: Yorktown Heights, 2010).

55. B. Arfaei, Y. Xing, J. Woods, J. Wolcott, P. Tumne, P. Borgesen, and E. Cotts, Proceedings of the Electronic Components and Technology Conference (IEEE, Orlando, FL, 2008), pp. 459-465.

56. F. Ochoa, X. Deng, and N. Chawla, J. Electron. Mater. 33, 1596 (2004).

57. M. Lu, D.Y. Shih, P. Lauro, C. Goldsmith, and D.W. Henderson, Appl. Phys. Lett. 92, 211909 (2008).

58. B. Arfaei, N. Kim, and E.J. Cotts, J. Electron. Mater. 41, $362(2012)$.

59. C.M. Gourlay, S.A. Belyakov, Z.L. Ma, and J.W. Xian, J. Met. 123, 404 (2015).

60. L.P. Lehman, Y. Xing, T.R. Bieler, and E. Cotts, Acta Mater. 58, 3546 (2010).

61. B. Arfaei, M. Benedict, and E. Cotts, J. Appl. Phys. 114, 173506 (2013).

62. F. Mutuku, B. Arfaei, and E.J. Cotts, J. Electron. Mater. 46, 3067 (2016).

63. J.W. Xian, Z.L. Ma, S.A. Belyakov, M. Ollivier, and C.M. Gourlay, Acta Mater. 123, 404 (2017).

64. B. Arfaei, L. Wentlent, S. Joshi, A. Alazzam, T. Tashtoush, M. Halaweh, S. Chivukula, L. Yin, M. Meilunas, E. Cotts, and P. Borgesen, Proceedings of the ITherm Conference (San Diego, CA, 2012), pp. 392-398.

65. Y. Zhang, Z. Cai, J.C. Suhling, P. Lall, and M. Bozak, Proceedings of the Electronic Components and Technology Conference (IEEE, Orlando, FL, 2008), pp. 99112.

66. T.K. Lee, T.R. Beiler, C.U. Kim, and H. Ma, Fundamentals of Lead-Free Solder Interconnect Technology (Boston: Springer, 2015), pp. 29-80.

67. B. Arfaei, M. Anselm, S. Joshi, S. Mahin-Shirazi, P. Borgesen, E. Cotts, J. Wilcox, and R. Coyle, Proceedings of the SMTA International Conference (Rosemont, IL, 2013), pp. 539-550.

68. S. Dunford, S. Canumalla, and P. Viswanadham, Proceedings of the Electronic Components and Technology Conference (IEEE, Las Vegas, NV, 2004), pp. 726-736.

69. L. Yin, L. Wentlent, L. Yang, B. Arfaei, A. Qasaimeh, and P. Borgesen, J. Electron. Mater. 41, 241 (2011).

70. T.T. Mattila and J.K. Kivilahti, IEEE Trans. Compon. Packag. Technol. 33, 629 (2010).

71. H.T. Chen, J. Han, J. Li, and M.Y. Li, Microelectron. Reliab. 52, 1112 (2012).

72. F. Yang and J.C.M. Li, J. Mater. Sci.: Mater. Electron. 18, 191 (2007).

73. P.W. Bridgman, Proc. Am. Acad. Arts Sci. 60, 305 (1925).

74. J. Bartelo, S.R. Cain, D. Caletka, K. Darbha, T. Gosselin, D.W. Henderson, D. King, K. Knadle, A. Sarkhel, G. Thiel, and C. Woychik, Proceedings of the IPC APEX Conference (San Diego, CA, 2001), pp. LF2-2 1-LF2-2 12.

75. E.H. Wong, W.D. van Driel, A. Dasgupta, and M. Pecht, Microelectron. Reliab. 59, 1 (2016).

76. P. Vianco, Opening Ceremony Presentation, SMTA International Conference, October 6, 2009.

77. B. Arfaei, S. Mahin-Shirazi, S. Joshi, M. Anselm, P. Borgesen, E. Cotts, J. Wilcox, and R. Coyle, Proceedings of the Electronic Components and Technology Conference (Las Vegas, NV, 2013), pp. 976-985.

78. D. Chan, X. Nie, D. Bhate, G. Subbarayan, W.W. Chen, and I. Dutta, IEEE Trans. Compon. Packag. Manuf. Technol. 3, 133 (2013)

79. S. Chavali, Y. Singh, P. Kumar, G. Subbarayan, I. Dutta, and D.R. Edwards, Proceedings of the Electronic Components and Technology Conference (IEEE, Orlando, FL, 2011), pp. 701-705.

80. I. Dutta, J. Electron. Mater. 32, 201 (2003).

81. I. Dutta, D. Pan, R.A. Marks, and S.G. Jadhav, Mater. Sci. Eng., A 410, 48 (2005).

82. P. Lall, K. Mirza, J. Suhling, and D. Locker, Proceedings of the Electronic Components and Technology Conference (IEEE, Orlando, FL, 2017), pp. 1285-1297. 